\title{
PENGARUH STRES KERJAD LINGKUNGAN KERJA FISIK TERHADAP KINERJA KARYAWAN PADA PURI SARON MADANGAN HOTEL DI KABUPATEN GIANYAR
}

\author{
Ni Luh Mariani ${ }^{1}$ \\ I Made Kartika ${ }^{2}$ \\ ${ }^{1,2}$ Fakultas Ekonomi Universitas Ngurah Rai Denpasar \\ e-mail: iluhmaryanii@yahoo.com
}

\begin{abstract}
ABSTRAK
Tujuan penelitian adalah : untuk mengetahui pengaruh stress kerja dan lingkungan kerja fisik secara parsial dan simultan terhadap kinerja karyawan. Penelitian ini dilakukan pada Puri Saron Madangan Hotel di Kabupaten Gianyar. Responden dalam hal ini sebanyak 35 orang. Responden dalam hal ini adalah karyawan pada Puri Saron Madangan Hotel di Kabupaten Gianyar. Data yang dikumpulkan dengan cara observasi, wawancara, dan Study dukumentasi: Regresi Linear berganda, determinasi, dan analisis statistik, uji t (t-test) dan analisis statistic uji F (F-test) merupakan teknik analisis yang dipergunakan . berdasarkan hasil analisis diperoleh hasil stress kerja dan lingkungan kerja fisiksecara parsial berpengaruh positif dan signifikan terhadap kinerja karyawan. Stress kerja dan lingkungan kerja fisik secara simultan berpengaruh positif dan signifikan terhadap kinerja karyawan. Koefisien determinasi menunjukkan kontribusi/sumbangan stress kerja dan lingkungan kerja fisik terhadap kinerja adalah 87,40\%sedangkan sisanya $12,60 \%$ dipengaruhi factor lain yang tidak dibahas.

Kata kunci: Stres Kerja, Lingkungan Kerja Fisik, Kinerja Karyawan.
\end{abstract}

\section{ABSTRACT}

The purpose of the study is : to determine the influence of work stress and physical work environment partially and simultaneously on employee performance. This research was conducted at Puri Saron Madangan Hotel at gianyar distric. Respondents in this case as many as 35 people. Respondents in this case are employes of Puri Saron Madangan Hotel At Gianyar distric. Data collected by observation, interview, and study documentation. Multiple linear regression, determination, and statistical analysis, $t$ test (t-test) and statistical analysis F test (F-test) is an analytical technique used. Based on the results of the analysis resultsobtained workstress and physical partially have a positive and significant impac on employee performance. Work stress and physical work environment simultaneously have a positive and significant effect on employeeperformance . the coefficient of determination shows contribution/ contribution of work stress and physical work environment to performent is $87,40 \%$ while the rest $12,60 \%$ influenced other factor not discussed.

Keyward: Work Stress, Physical work environment, Employee Performance. 


\section{PENDAHULUAN}

Perkembangan perekonomian di Indonesia ditopang oleh beberapa sektor ekonomi, berdasarkan data Badan Pusat Statistik Nasional menyatakan bahwa terdapat 10 sektor lapangan pekerjaan utama yang menopang perekonomian di Indonesia. Salah satu sektor yang memiliki peran penting dalam perekonomian adalah sektor Pariwisata yang meliputi Perdagangan, Rumah Makan, dan Jasa Akomodasi. Menurut Badan Pusat Statistik Nasional, pada bulan Februari 2013 Sektor Pariwisata menduduki peringkat ke-2 setelah sektor Pertanian, Perkebunan, Kehutanan dan Perikanan yang menyerap tenaga kerja paling banyak. Data Badan Pusat Statistik Nasional menyatakan bahwa dari 114 juta angkatan kerja pada semester pertama, 24 juta angkatan kerja bekerja pada bidang Perdagangan dan Jasa Akomodasi. Oleh karena itu, dapat dikatakan bahwa pariwisata memegang peranan penting dalam menunjang perekonomian di Indonesia.

Bali merupakan salah satu daerah tujuan wisata utama di Indonesia yang sudah terkenal sampai ke mancanegara dan memiliki kedudukan yang dapat di sejajarkan dengan daerah-daerah tujuan wisata lainnya yang ada di dunia. Sebagai daerah tujuan wisata utama di Indonesia, Bali telah mendapatkan perhatian dari pemerintah dalam mengembangkan pariwisata khususnya di Indonesia Bagian Tengah. Pengembangan pariwisata di Bali telah mengalami kemajuan yang sangat pesat baik dari kualitas maupun kuantitas. Hal tersebut, dapat dilihat dari perkembangan dan bertambahnya sarana dan prasarana pariwisata seperti akomodasi, transportasi, fasilitas rekreasi, hiburan dan atraksi wisata. Tidak hanya itu dari segi sumber daya manusia, Bali terus menambah kuantitas, serta meningkatkan kualitas dan mutu para pekerja di sektor pariwisata melalui berbagai cara salah satunya pelatihan intensif.

Bali memiliki keunikan dan keunggulan kebudayaan, yaitu adanya perpaduan yang harmonis antara potensi kebudayaan dan sumber daya manusia yang kreatif dengan dukungan alam yang mempesona menjadi modal dasar untuk menopang keunggulan kompetitif pariwisata daerah Bali. Tingginya minat wisatawan dapat dilihat dari jumlah kunjungan wisatawan ke Bali dalam 5 tahun terakhir pada tabel dibawah ini.

Tabel 1 Jumlah Kunjungan Wisatawan Asing Yang Datang Ke Bali Tahun 20112015.

\begin{tabular}{ccc}
\hline \hline Tahun & $\begin{array}{c}\text { Jumlah Wisatwan } \\
\text { (orang) }\end{array}$ & $\begin{array}{c}\text { Pertumbuhan } \\
(\%)\end{array}$ \\
\hline 2011 & 1.664 .854 & - \\
2012 & 1.968 .892 & 18,26 \\
2013 & 2.229 .954 & 13,26 \\
2014 & 2.493 .058 & 11,76 \\
2015 & 2.756 .579 & 10,57 \\
\hline Total & 11.113 .328 & 58,88 \\
\hline Rata-rata & 2.222 .667 & 10,78 \\
\hline \hline
\end{tabular}

Sumber : Dinas Pariwisata Bali 
Berdasarkan data tabel 1.1 dapat dilihat bahwa kunjungan wisatawan asing yang datang ke Bali mengalami naik dan turun pada setiap tahunnya dengan rata-rata pertumbuhan $10,78 \%$, dengan tingkat pertumbuhan tinggi pada tahun 2012 sebesar $18,26 \%$ dan mengalami penurun pada tahun 2015 sebesar $10,57 \%$.

Mengingat kelangsungan hidup perusahaan tergantung kepada sumber daya manusia yang bekerja baik, salah satu kebijakan yang dapat diambil untuk memperoleh karyawan yang bekerja baik adalah dengan memperhatikan kinerja karyawan. Menurut Handoko (2001: 135) Kinerja karyawan merupakan suatu tindakan yang dilakukan karyawan dalam melaksanakan pekerjaan yang diberikan perusahaan. Setiap perusahaan selalu mengharapkan karyawannya mempunyai prestasi, karena dengan memiliki karyawan yang berprestasi akan memberikan sumbangan yang optimal bagi perusahaan. Faktor-faktor yang mempengaruhi kinerja karyawan yaitu stress kerja dan lingkungan kerja fisik.

Stress merupakan suatu kondisi keadaan seseorang mengalami ketegangan karena adanya kondisi yang mempengaruhinya, kondisi tersebut dapat diperoleh dari dalam diri seseorang maupun lingkungan diluar diri seseorang. Stress dapat menimbulkan dampak yang negatif terhadap keadaan psikologis dan biologis bagi karyawan. Menurut Stephen P. Robbin dalam Badeni (2014:62) stress adalah suatu kondisi dinamik yang didalamnya seorang individu dihadapkan dengan suatu peluang, kendala, atau tuntutan yang berkaitan dengan apa yang ia inginkan dan hasilnya dipersepsikan sebagai yang tidak pasti dan penting. Sedangkan menurut Mangkunegara (2005) stress adalah perasaan yang menekan atau merasa tertekan yang dialami karyawan dalam menghadapi pekerjaan.

Selain faktor stress kerja yang mempengaruhi kinerja karyawan adalah lingkungan kerja fisik. Lingkungan kerja fisik merupakan suatu lingkungan dimana para karyawan bekerja dan dapat mempengaruhi mereka dalam menjalankan tugas-tugas yang dibebankan. Menurut Nitisemito (2000: 109) Lingkungan kerja fisik adalah segala sesuatu yang ada di sekitar pekerja dan yang dapat mempengaruhi dirinya dalam menjalankan tugas-tugas yang dibebankan. Sedangkan menurut Robbins (2006: 86) lingkungan kerja fisik adalah pengaturan- pengaturan terhadap kebersihan, pertukaran udara, penerangan, keamanan dan kebisingan.

Puri Saron Madangan Hotel di Gianyar adalah hotel yang terletak di Desa Madangan Petak Gianyar. Puri Saron Madangan Hotel di Gianyar merupakan salah satu perusahaan yang bergerak di sektor pariwisata dalam bidang pelayanan jasa(service). Hal ini dapat dibuktikan dari jumlah kunjungan wisatawan ke Puri Saron Madangan Hotel di Gianyar selama periode tahun 2011 sampai 2015. 
Tabel 2 Jumlah Kunjungan Wisatawan Ke Puri Saron Madangan Hotel di Gianyar

\begin{tabular}{ccc}
\hline \hline Tahun & Domestik & Asing \\
\hline 2011 & 788 & 570 \\
2012 & 595 & 509 \\
2013 & 325 & 442 \\
2014 & 418 & 312 \\
2015 & 489 & 347 \\
\hline Total & 2615 & 2180 \\
\hline
\end{tabular}

Sumber : Puri Saron Madangan Hotel di Gianyar

Berdasarkan data tabel 1.2 dapat dilihat bahwa kunjungan wisatawan asing maupun domestik yang berkunjung ke Puri Saron Madangan Hotel di Gianyar dari tahun 2011 sampai 2015 mengalami penurunan setiap tahunnya, dimana penurunan jumlah kunjungan wisatawan domestik tertinggi terjadi pada tahun 2013 yaitu sebanyak 270 orang, sedangkan penurunan jumlah kunjungan wisatawan asing tertinggi pada tahun 2014 yaitu sebanyak 130 orang. Secara teoritis kinerja karyawan tercermin dari beberapa indikator, salah satunya adalah tingkat absensi karyawan.

Adapun tingkat absensi karyawan pada Puri Saron Madangan Hotel di Gianyar dapat dilihat pada tabel dibawah ini.

Tabel 3: Tingkat Absensi Karyawan Pada Puri Saron Madangan Hotel di Gianyar Tahun 2015

\begin{tabular}{|c|c|c|c|c|c|c|c|}
\hline No & Bulan & $\begin{array}{l}\text { Jumlah } \\
\text { tenaga } \\
\text { kerja } \\
\text { (orang) }\end{array}$ & $\begin{array}{l}\text { Jumlah } \\
\text { hari kerja } \\
\text { (hari) }\end{array}$ & $\begin{array}{l}\text { Jumlah hari } \\
\text { kerja } \\
\text { seharusnya } \\
\text { (hari) }\end{array}$ & $\begin{array}{l}\text { Jumlah } \\
\text { hari kerja } \\
\text { yang telah } \\
\text { hilang } \\
\text { (hari) }\end{array}$ & $\begin{array}{l}\text { Jumlah hari } \\
\text { kerja } \\
\text { senyatanya } \\
\text { (hari) }\end{array}$ & $\begin{array}{l}\text { Persentase } \\
\text { absensi (\%) }\end{array}$ \\
\hline 1 & 2 & 3 & 4 & $5=(3 X 4)$ & 6 & $7=(5-6)$ & $8=(6: 5)$ \\
\hline 1 & Januari & 35 & 26 & 910 & 15 & 895 & 1,64 \\
\hline 2 & Februari & 35 & 24 & 840 & 12 & 828 & 1,42 \\
\hline 3 & Maret & 35 & 26 & 910 & 15 & 895 & 1,64 \\
\hline 4 & April & 35 & 25 & 875 & 13 & 862 & 1,48 \\
\hline 5 & Mei & 35 & 25 & 875 & 12 & 863 & 1,37 \\
\hline 6 & Juni & 35 & 25 & 875 & 13 & 862 & 1,48 \\
\hline 7 & Juli & 35 & 26 & 910 & 14 & 896 & 1,53 \\
\hline 8 & Agustus & 35 & 25 & 875 & 13 & 862 & 1,48 \\
\hline 9 & September & 35 & 25 & 875 & 13 & 862 & 1,48 \\
\hline 10 & Oktober & 35 & 26 & 910 & 15 & 895 & 1,64 \\
\hline 11 & November & 35 & 25 & 875 & 13 & 862 & 1,48 \\
\hline 12 & Desember & 35 & 26 & 910 & 15 & 895 & 1,64 \\
\hline & Jumlah & 420 & 304 & 10640 & 163 & 10477 & 18,28 \\
\hline & Rata-rata & 35 & 25,33 & 866,67 & 13,6 & 873,1 & 1,52 \\
\hline
\end{tabular}

Sumber : Puri Saron Madangan Hotel di Gianyar 
Dari tabel 1.3 dapat dijelaskan bahwa tingkat absensi karyawan pada Puri Saron Madangan Hotel di Gianyar tahun 2015 cenderung berfluktuasi setiap bulannya dimana rata-rata tingkat absensi karyawan sebesar 1,52\% menunjukkan tingkat absensi rendah atau dapat dikatakan kinerja karyawan tinggi. Menurut Flippo mengatakan bahwa jumlah tingkat absensi berada di $0 \%$ sampai dengan $2 \%$ artinya baik.

Meskipun demikian kinerja karyawan masih terlihat kurang optimal dalam bekerja dikarenakan masih ada pekerjaan yang diselesaikan tidak tepat waktu, kurang kepercayaan diri disaat berhadapan dengan tamu dan lain-lain.

Usaha untuk meningkatkan kinerja karyawan, diantaranya adalah karyawan harus mampu bekerja dengan baik tanpa mengalami stress dalam bekerja. Berdasarkan hasil wawancara yang dilakukan dengan beberapa karyawan Puri Saron Madangan Hotel di Gianyar, masih banyak karyawan yang mengalami stress di dalam melakukan pekerjaan dikarenakan hubungan antar rekan kerja kurang baik sehingga terjadi konflik, seringnya perubahan jadwal kerja yang diberikan oleh atasan juga menjadi pemicu stress pada karyawan, gaji yang diterima waktunya sering berubah-ubah tidak sesuai dengan komitmen perusahaan.

Selain stress kerja, lingkungan kerja fisik juga menjadi perhatian untuk meningkatkan kinerja karyawan. Hal-hal yang menjadi perhatian dari lingkungan kerja fisik di Puri Saron Madangan Hotel di Gianyar adalah ruangan, penerangan, gangguan dalam ruangan, keadaan udara (kelembaban, temperatur, sirkulasi udara) dan kebersihan. Ada beberapa keluhan dari karyawan mengenai lingkungan kerja fisik yaitu penerangan yang kurang dan ruangan loker yang sempit menyulitkan karyawan pada saat menaruh barang diloker, areal parkir yang sempit.

Berdasarkan latar belakang diatas, maka penelitian ini ingin mengetahui pengaruh stress kerja dan lingkungan kerja fisik terhadap kinerja karyawan dalam perusahaan, oleh karena itu maka perlu dilakukan penelitian dengan judul "Pengaruh Stres Kerja dan Lingkungan Kerja Fisik Terhadap Kinerja Karyawan Pada Puri Saron Madangan Hotel di Gianyar"

\section{METODE PENELITIAN}

Penelitian ini berlokasi pada Puri Saron Madangan Hotel di Kabupaten Gianyar yang berlokasi di Desa Madangan Petak, Gianyar. Adapun yang menjadi obyek penelitian adalah stress kerja, lingkungan kerja fisik dan kinerja karyawan pada Puri Saron Madangan Hotel di Kabupaten Gianyar. Penelitian pada Puri Saron Madangan Hotel menggunakan 2 variabel bebas yaitu stress kerja , lingkungan kerja fisik dan 1 variabel terikat ya itu kinerja karyawan. Untuk mendefinisikan suatu variabel yang terkait dengan objek penelitian, maka dibuat beberapa pengertian batasan operasional variabel, yaitu : 1) Stres Kerja (X1) Stres Kerja merupakan suatu respon atau reaksi karyawan Puri Saron Madangan Hotel di Kabupaten Gianyar yang muncul karena adanya situasi tertentu yang menimbulkan stres.

2) Lingkungan Kerja Fisisk (X2) LIngkungan Kerja Fisik adalah segala sesuatu yang ada di Puri Saron Madangan Hotel di Kabupaten Gianyar yang dapat mempengaruhi dirinya dalam menjalankan tugas-tugas yang dibebankan. 3) Kinerja Karyawan (Y) Kinerja merupakan suatu kondisi yang harus diketahui dan di konfirmasikan kepada pihak tertentu untuk mengetahui 
tingkat pencapaian hasil, suatu intansi di hubungkan dengan visi yang di emban Puri Saron Madangan Hotel di Kabupaten Gianyar serta mengetahui dampak positif dan negative dari suatu kebijakan operasional.

Penelitian ini menggunakan jenis data : Kuantitatif dan Kualitatfi dan sumber data : primer dan skunder. Penentuan sampel dalam penelitian ini menggunakan sampel jenuh dimana seluruh karyawan di jadikan responden, jadi sampel yang digunakan dalam penelitian ini sebanyak 35 orang karyawan. Metode pengumpulan data menggunakan metode observasi, wawancara, kuisoner dan dokumentasi.

Teknik Analisis data dalam penelitian ini menggunakan Analisis Regresi Linier Berganda analisis ini dipergunakan untuk mengetahui perubahan variabel terikat yang dipengaruhi oleh variabel bebas. Analisis Determinasi digunakan untuk mengetahui jumlah presentase kontribusi stres kerja dan lingkungan kerja fisik terhadap kinerja karyawan. Analisis uji t
Analisis ini digunakan untuk menguji nyata tidaknya pengaruh variabel bebas (X) dengan variabel terikat (Y). Analisis uji $\mathrm{F}$ digunakan untuk menguji pengaruh stress kerja dan lingkungan kerja fisik terhadap kinerja karyawan secara simultan. Untuk mengetahui pengaruh stress kerja dan lingkungan kerja fisik terhadap kinerja karyawan, dalam penelitian ini menggunakan bantuan Statistical Package for Social Science 21 (SPSS).

\section{HASIL DAN PEMBAHASAN}

Teknis analisis data dalam penelitian ini menggunakan analisis regresi linier berganda, dengan tujuan untuk menguji pengaruh stres kerja dan lingkungan kerja fisik terhadap kinerja karyawan pada Puri Saron Madangan Hotel Gianyar, dengan menggunakan aplikasi SPSS (Statistical Product and Service Solution) version 21.0 for windows maka hasil analisis yang diperoleh seperti yang diuraikan pada tabel 5.11 berikut:

Tabel 4. Hasil Analisis SPSS Version 21.0 For Windows, Pengaruh Stres Kerja dan Lingkungan Kerja Fisik Pada Puri Saron Madangan Hotel di Kabupaten Gianyar tahun 2016

\begin{tabular}{|c|c|c|c|c|}
\hline Variabel & & Koefisien Regresi & t-hitung & Signifikan t \\
\hline$(1)$ & & $(2)$ & (3) & (4) \\
\hline Konstanta & & $-24,729$ & $-5,556$ & 0,000 \\
\hline Stres Kerja & & 0,569 & 2,625 & 0,013 \\
\hline $\begin{array}{l}\text { Lingkungan } \\
\text { Fisik }\end{array}$ & Kerja & 1,303 & 5,796 & 0,000 \\
\hline $\mathrm{R}$ & & $=0,935$ & & \\
\hline $\mathrm{R}^{2}$ & & $=0,874$ & & \\
\hline & & $=111,458$ & & \\
\hline Signifikan F & & $=0,000$ & & \\
\hline
\end{tabular}

Sumber :lampiran 4(data primer diolah) 
Berdasarkan Tabel 5.11 tersebut di atas, maka persamaan regresi linier berganda adalah: $\mathrm{Y}=-24.729+0,569$ $\left(\mathrm{X}_{1}\right)+1,303\left(\mathrm{X}_{2}\right)$, dengan penjelasan sebagai berikut:

a. Nilai $a=-24.729$ artinya bahwa jika stres kerja dan lingkungan kerja fisik nilainya adalah 0 (nol), maka kinerja karyawan nilainya adalah sebesar 24.729

b. Nilai $b_{1}=0,569$ artinya jika variabel stress kerja mengalami kenaikan sebesar 1 satuan, maka kinerja karyawan akan mengalami kenaikan sebesar 0,569 satuan.

c. Nilai $b_{2}=1,303$ artinya jika variabel lingkungan kerja fisik mengalami kenaikan sebesar 1 satuan, maka kinerja karyawan akan mengalami kenaikan sebesar 1,303 satuan.

\subsubsection{Analisis Koefisien Determinasi}

Analisis determinasi digunakan untuk mengetahui besarnya kontribusi sumbangan stres kerja dan lingkungan kerja fisik terhadap kinerja karyawan, yang dinyatakan dalam persentase. Berdasarkan analisis program SPSS Version 21,0 for Windows pada tabel $5.11 \mathrm{di}$ atas diperoleh hasil besarnya $\mathrm{R}^{2}=$ 0,874 jadi besarnya koefisien Determinasi ( $\mathrm{D}=87,40 \%)$. Hal ini menunjukkan bahwa persentase kontribusi sumbangan stres kerja dan lingkungan kerja fisik terhadap kinerja karyawan adalah sebesar 87,40 \% . Sedangkan sisanya sebesar 12,60\% dipengaruhi atau dijelaskan oleh variabel lain yang tidak dibahas dalam penelitian ini.

\subsubsection{Analisis Statistik uji-t (t-test)}

Analisis uji t ( t-test ) digunakan untuk menguji signifikansi pengaruh stress kerja dan lingkungan kerja fisik secara parsial terhadap kinerja karyawan adalah pengaruh yang positif dan signifikan atau hanya kebetulan saja.

a) Pengaruh Stress Kerja Terhadap Kinerja Karyawan

1) Merumuskan Hipotesis

$$
\begin{aligned}
\mathrm{H}_{\mathrm{o}}: \beta_{1}= & 0, \text { artinya tidak ada } \\
& \text { pengaruh positif dan } \\
& \text { signifikan antara stress } \\
& \text { kerja terhadap kinerja } \\
& \text { karyawan pada Puri } \\
& \text { Saron Madangan } \\
& \text { Hotel. } \\
\mathrm{H}_{\mathrm{a}}: \beta_{1}> & 0, \text { artinya ada } \\
& \text { pengaruh positif dan } \\
& \text { signifikan antara stress } \\
& \text { kerja terhadap kinerja } \\
& \text { karyawan pada Puri } \\
& \text { Saron } \\
& \text { Hotel. }
\end{aligned}
$$

2) Menentukan t-tabel

Dengan menggunakan derajat kepercayaan $95 \%$ atau tingkat kesalahan $5 \%(\alpha=0,05)$ maka nilai df yang diperoleh adalah sebesar $\mathrm{df}=\mathrm{n}-\mathrm{k}$ atau $\mathrm{df}=35-3=32$ ( $\mathrm{n}$ adalah jumlah kasus dan $\mathrm{k}$ adalah jumlah variabel ), test 1 sisi pada sisi kanan, maka t-tabel $=\mathrm{t} \alpha(\mathrm{n}-\mathrm{k})$ sehingga hasil yang diperoleh t-tabel t $\alpha(0,05 ; 32)$ adalah sebesar _ 1,694 (Lihat : Lampiran 5).

3) Perhitungan nilai t-hitung

Berdasarkan pada Tabel 5.11 maka diporeleh nilai t-hitung sebesar 2,625.

4) Kriteria pengujian Jika $\mathrm{t}_{1}$-hitung $>\mathrm{t}$-tabel, maka Ho ditolak dan Ha diterima Jika $t_{1}$-hitung < $\mathrm{t}$-tabel, maka Ho diterima dan Ha ditolak

5) Menggambar daerah penerimaan dan penolakan Ho untuk membuktikan Ho diterima atau ditolak, sesuai dengan hipotesis 
yang dibuat, maka dapat digambarkan dalam sebuah kurva daerah penerimaan dan penolakan Ho sebagai berikut:

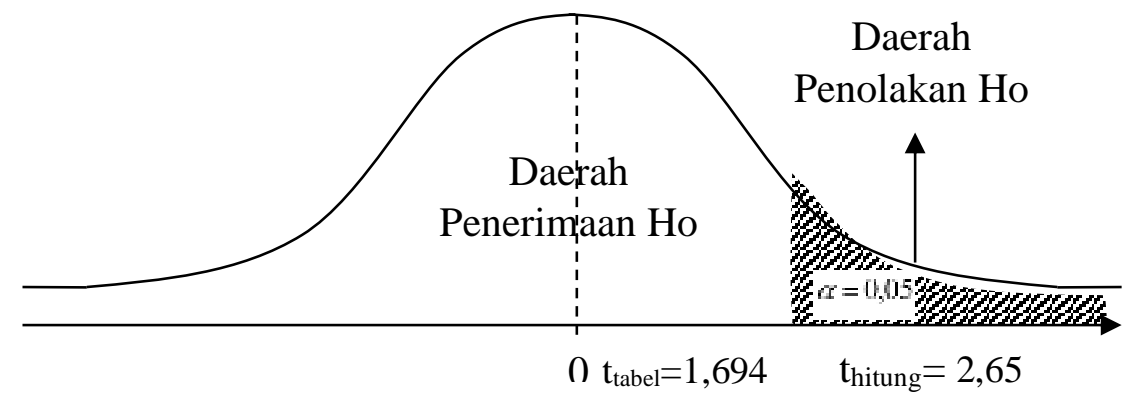

6) Kesimpulan.

Berdasarkan hasil analisis gambar 5.1 di atas menunjukkan bahwa nilai $t_{1}$-hitung di peroleh sebesar 2,625 sedangkan t-tabel sebesar 1,694 . Ternyata nilai $t_{1-}$ hitung lebih besar daripada ttabel atau t-hitung $=2,625>\mathrm{t}$ tabel $=1,694$. Maka Ho ditolak dan Ha diterima. Hal ini berarti bahwa stress kerja mempunyai pengaruh positif dan signifikan terhadap kinerja karyawan pada Puri Saron Madangan Hotel di Kabupaten Gianyar.

b) Pengaruh Lingkungan Kerja Fisik Terhadap Kinerja Karyawan

1) Merumuskan Hipotesis

Ho: $\beta_{2}=0$, artinya tidak ada pengaruh positif dan signifikan antara lingkungan kerja fisik terhadap kinerja karyawan pada Puri Saron Madangan Hotel.

Ha : $\beta_{2}>0$, artinya ada pengaruh positif dan signifikan antara

lingkungan kerja fisik terhadap kinerja karyawan pada Puri Saron Madangan Hotel.

2) Menentukan t-tabel

Dengan menggunakan derajat kepercayaan $95 \%$ atau tingkat kesalahan $5 \%(\alpha=0,05)$ maka nilai df yang diperoleh adalah sebesar $\mathrm{df}=\mathrm{n}-\mathrm{k}$ atau $\mathrm{df}=35-3=32$, test 1 sisi pada sisi kanan, maka t-tabel adalah sebesar 1,694 (Lihat: Lampiran 5).

3) Menentukan t-hitung

Berdasarkan data pada Tabel 5.11 maka diperoleh nilai $\mathrm{t}_{2}$ hitung sebesar 5,796.

4) Kriteria Pengujian

(1) Jika t $t_{2}$-hitung $>$ t-tabel, maka Ho ditolak dan Ha diterima

(2) Jika $t_{2}$-hitung $\leq$ t-tabel, maka Ho diterima dan Ha ditolak

5) Menggambar daerah penerimaan dan penlokan Ho. Untuk membuktikan Ho diterima atau ditolak, sesuai dengan hipotesis yang dibuat, maka dapat digambarkan dalam sebuah kurva 
daerah penerimaan dan penolakan

hipotesis sebagai berikut:

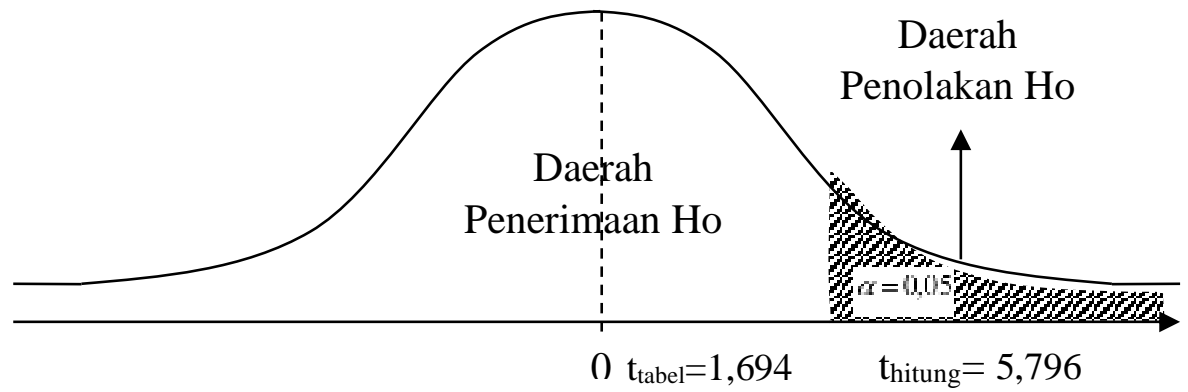

6) Kesimpulan

Sesuai dengan gambar 5.2 menunjukkan bahwa nilai t2hitung diperoleh sebesar 5,796 sedangkan nilai t-tabel sebesar 1,694, ternyata nilai t2-hitung lebih besar dari pada t-tabel atau t2-hitung $=5,796>$ t-tabel $=$ 1,694 maka Ho ditolak dan Ha diterima. Hal ini berarti lingkungan kerja fisik mempunyai pengaruh postif dan signifikan terhadap kinerja karywan pada Puri Saron Madangan Hotel di Kabupaten Gianyar.

\subsubsection{Analisis Uji Statistik F ( F-test)}

Analisis Uji Statistik F (FTest) digunakan untuk menguji signifikansi stress kerja dan lingkungan kerja fisik ecara simultan terhadap kinerja karyawan. Pengujian ini dilakukan dengan menggunakan langkah-langkah pngujian hipotesis sebagai berikut:

1) Merumuskan Hipotesis

Ho : $\beta_{1} ; \beta_{2}=0$, artinya tidak ada pengaruh positif dan signifikan secara simultan antara stress kerja dan lingkungan kerja fisik terhadap kinerja karyawan pada Puri Saron Madangan Hotel.

Ha : $\beta_{1} ; \beta_{2}>0, \quad$ artinya ada pengaruh positif dan signifikan secara simultan antara stress kerja dan lingkungan kerja fisik terhadap kinerja karyawan pada Puri Saron Madangan Hotel.

2) Menentukan F-tabel

Dengan menggunakan derajat kepercayaan $95 \%$ atau tingkat kesalahan $5 \%(\alpha=0,05)$ maka nilai df (degree of freedom) atau derajat bebas pembilang $=\mathrm{k}-1=3-2=1$ dan derajat bebas penyebut $=\mathrm{n}-\mathrm{k}=35$ $3=32$, maka diperoleh F-tabel $=_{\alpha\left(\mathrm{k}^{-}-1\right)(\mathrm{n}-}$ $\mathrm{k})=\mathrm{F}_{(0,05(2)(32)}=3,295$ (lihat lampiran 6)

3) Menentukan F-hitung

Berdasarkan data pada Tabel 5.11 maka diperoleh nilai F-hitung sebesar 111,458 .

4) Kriteria Pengujian

a) Jika F-hitung > F-tabel, maka Ho ditolak dan Ha diterima.

b) Jika F-hitung $\leq$ F-tabel, maka Ho diterima dan Ho ditolak.

5) Menggambar daerah penerimaan dan penolakan Ho untuk membuktikan Ho diterima atau ditolak, sesuai dengan hipotesis 
yang diukur, maka dapat digambarkan dalam sebuah kurva

daerah penerimaan dan penolakan hipotesis sebagai berikut:

Gambar 1. Daerah Penerimaan dan Penolakan Ho

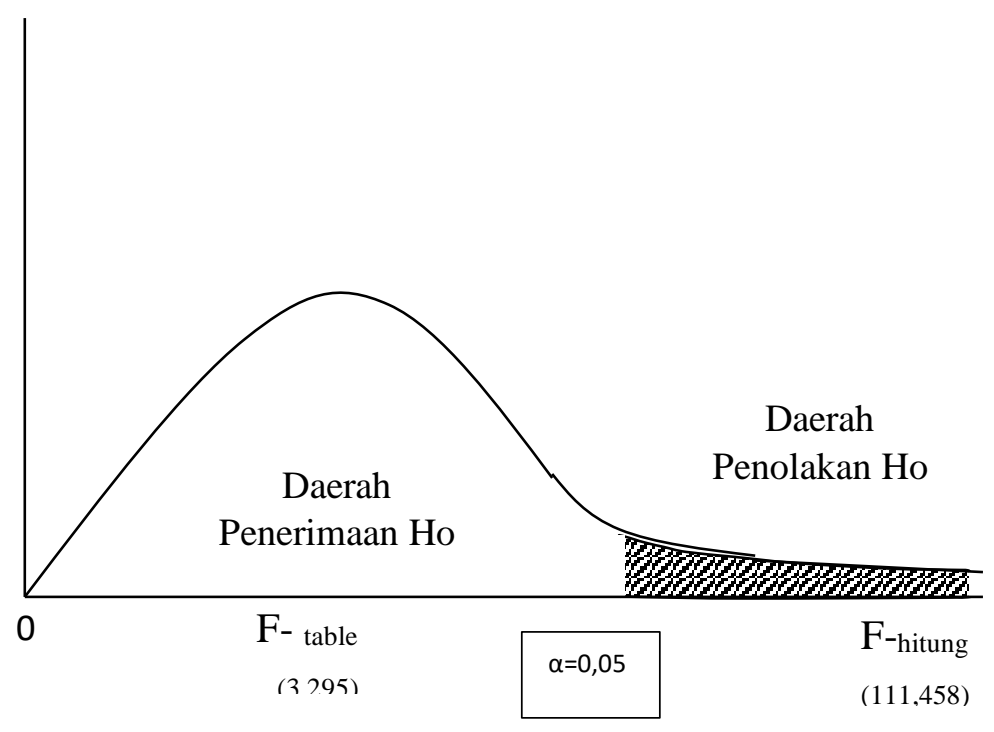

6) Kesimpulan

Berdasrkan hasil analisis gambar 5.3 di atas menunjukkan bahwa nilai Fhitung diperoleh sebesar $=111,458$ sedangkan nilai F-tabel sebesar $=$ 3,295, ternyata nilai F-hitung lebih besar daripada F-tabel atau F-hitung $=111,458>$ F-tabel $=3,295$, maka Ho ditolak dan Ha diterima. Hal ini berarti bahwa stress kerja dan lingkungan kerja fisik mempunyai pengaruh positif dan signifikan terhadap kinerja karyawan pada Puri Saron Madangan Hotel di Kabupaten Gianyar.

\section{Simpulan}

Hasil penelitian dan pembahasan yang telah diuraikan pada bab sebelumnya, maka dapat ditarik kesimpulan sebagai berikut :

a. Jika dilihat dari pengaruh stress kerja terhadap kinerja karyawan pada Puri
Saron Madangan Hotel Gianyar di Gianyar sesuai dengan hasil penelitian menunjukkan bahwa nilai t-hitung > t-tabel $(2,625>1,694)$ serta nilai signifikansi sebesar 0,013 , hal ini menunjukkan bahwa "Ada pengaruh positif dan signifikan antara stress kerja terhadap kinerja karyawan pada Puri Saron Madangan Hotel di Gianyar"

b. Sementara hasil pengaruh lingkungan kerja fisik terhadap kinerja karyawan pada Puri Saron Madangan Hotel Gianyar di Gianyar menunjukkan bahwa nilai t-hitung > t-tabel $(5,796>$ 1,694) serta nilai signifikansi sebesar 0,000 , hal ini menunjukkan bahwa "Ada pengaruh positif dan signifikan antara lingkungan kerja fisik terhadap kinerja karyawan pada Puri Saron Madangan Hotel di Gianyar"

c. Berdasarkan hasil pengaruh stress kerja dan lingkungan kerja fisik 
terhadap kinerja karyawan pada Puri Saron Madangan Hotel Gianyar di Gianyar menyatakan bahwa nilai Fhitung > F-tabel $(111,458>3,295)$ serta nilai signifikansi sebesar 0,000 lebih kecil dari 0,05 , hal ini menunjukkan bahwa "Ada pengaruh positif dan signifikan secara simultan antara stress kerja dan lingkungan kerja fisik terhadap kinerja karyawan pada Puri Saron Madangan Hotel di Gianyar".

\section{Saran}

Dari hasil pembahasan dan kesimpulan yang telah diuraikan di atas, maka diajukan beberapa saran yang diharapkan akan memberikan manfaat bagi peningkatan kinerja karyawan, yaitu :

a. Puri Saron Madangan Hotel di Gianyar diharapkan untuk mengatasi stres kerja karyawan terutama untuk tugas-tugas yang diberikan kepada karyawan terkadang terlalu sulit dan kompleks karena memiliki total point yang lebih rendah dibandingkan dengan yang lainnya. Hal ini dapat dilakukan dengan memberikan kemudahan karyawan untuk menyelesaikan tugas-tugas yang diberikan agar dapat meningkatkan kinerja karyawan.

b. Manajemen Puri Saron Madangan Hotel di Gianyar perlu memberikan perhatian supaya tercipta lingkungan kerja yang kondusif agar karyawan merasa lebih nyaman dalam bekerja baik di lingkungan fisik maupun di lingkungan non fisik. Sedangkan lingkungan non fisik dapat dengan mengadakan liburan bersama atau outbound untuk meningkatkan hubungan karyawan dengan pempinan maupun antar karyawan.

\section{REFERENSI}

Arikunto, Suharsini. 2006. Suatu Pendekatan Praktik. Jakarta: Rineka Cipta.

Badan Pusat Statistik Provinsi Bali. 2012. Diakses tanggal 20 Maret 2017. www.bps.go.id

Badan Pusat Statistik Kabupaten Gianyar. 2012. Diakses tanggal 27 Maret 2017. www.gianyarkab.bps.go.id

Badeni. 2014. Kepemimpinan dan Perilaku Organisasi. Cetakan kedua. Bandung: Alfabeta

Cherrington, David J. 1995. The Management Of Human Resources. Forth edition. Prentice Hall (Englewood Cliffs.N.J)

Endar, Sugiarto. 2001. Pengantar Akomodasi dan Restoran. Jakarta : Gramedia.

Ezy Tirtha Nadi, Dewa Ayu. 2014. Pengaruh Stres Kerja Dan Lingkungan Kerja Non Fisik Terhadap Kinerja Karyawan pada PT POS Indonesia (PERSERO) Gianyar. Skripsi (tidak diterbitkan) Denpasar: Program Manajemen Universitas Ngurah Rai Denpasar

Flippo, Edwin B. 2005. Manajemen Personalia Edisi Keenam. Jakarta: Raja Grafindo.

Gorda, I Gusti Ngurah 2003. Manajemen Sumber Daya Manusia. Bali, Denpasar: Cetakan ketiga. Asta Brata

Handoko, T. Hani. 2001. Manajemen Personalia dan Sumber Daya Manusia. Yogyakarta: BPFE 
Hariandja, Marihot Tua Efendi. Manajemen Sumber Daya Manusia. $2005 . \quad$ Jakarta: Gramedia Widiasarana.

Hasibuan, Melayu. 2004. Manajemen Sumber Daya, Manusia. Jakarta: Bumi Aksara.

Iin Melindasari.2015. Pengaruh Lingkungan Kerja dan Stres Kerja Terhadap Kinerja Karyawan pada PT. Federal Internasional Finance (FIF) Gresik. Jurnal. Surabaya. Universitas Wijaya Putra.

Mahmudi. 2005. Manajemen Kinerja Sektor Publik. Yogyakarta: UPP AMP YKPN.

Mangkunegara, Anwar Prabu. 2001. Manajemen Sumber Daya Manusia Perusahaan. Bandung: PT Remaja Rosdakarya. 2005.

Perilaku dan Budaya Organisasi. Bandung: PT. Refika Aditama.

Nitisemito,A.S. 2000. Manajemen Personalia (manajemen Sumber Daya Manusia) Edisi kedua. Jakarta. Ghalia Indonesia

Pabunda, Tika. 2006. Budaya Organisasi dan Peningkatan Kinerja Perusahaan. Jakarta: Bumi Aksara.

Rivai, Veithzal. 2009. Manajemen Sumber Daya Manusia Untuk Perusahaan Dari Teori Ke Praktek. Cetakan Pertama. Jakarta: PT. Raja Grafindo Persada.

Robbins. S.P. 2006. Perilaku Organisasi. Edisi Kesepuluh. Klaten: PT. Intan Sejati Klaten.

Sudjana. 2003. Teknik Analisis Regresi dan Korelasi. Bandung: Tarsito.

Sugiyono. 2010. Metode Penelitian Bisnis. Bandung: CV Alfabeta.

$\begin{array}{lr}\text { Pendidikan.Cetakan } & \text { Penelitian } \\ \text { Bandung: Alfabeta } & 14 .\end{array}$

Sulastiyono, Agus. 2011. Manajemen Penyelengara Hotel Seri Manajemen Usaha Jasa Sarana Pariwisata dan Akomodasi. Bandung : Alfabeta

Sunyoto, Danang. 2015. Teori Perilaku Keorganisasian. Cetakan Pertama. Yogyakarta: CAPS (Center of Academy)

Sutrisno, Edy. 2009. Manajemen Sumber Daya Manusia. Edisi Pertama. Jakarta: Prenadamedia Group.

Sedarmayanti. 2001. Sumber Daya Manusia dan Produktivitas Kerja. Bandung: Mandar Maju.

Yunus, Rahmat. 2014. Pengaruh Lingkungan Kerja Dan Stres Kerja Terhadap PT Hadji Kalla Alauddin Makasar. Jurnal. Program Manajemen Universitas Hasanuddin.Makasar. 